\title{
Absceso Prostático: diagnóstico y tratamiento clínico a propósito de un caso
}

\author{
Julio Andres Alvarez Ortiz \\ julioalvarezuro@gmail.com \\ Médico Residente del Servicio de Urología del Sanatorio del Salvador \\ (Córdoba - Argentina)
}

Karla Christina Enríquez Lozada

enriquezkarla2494@gmail.com

Médico Residente Clínica Conocoto

(Quito - Ecuador)

\section{Carolina Michelle Ludeña Benalcazar}

carolinatb@ hotmail.com

Médico Residente del Hospital General Enrique Garcés

(Quito - Ecuador)

Julia Inés Reyes Cevallos

julitines@hotmail.com

Médico Residente del Hospital General

De la Segunda División del Ejército "Libertad"

(Guayaquil - Ecuador)

Johanna Daniela Moya Proaño

Johanna1137@ hotmail.com

Médico Residente del Hospital General

De la Segunda División del Ejército "Libertad"

(Guayaquil - Ecuador)

Evelyn Andrea Vera Cevallos evelynvera20@gmail.com Médico en Libre Ejercicio de la Profesión

(Quito - Ecuador)

Melissa Dayana Mena Cabezas

melissamenacabezas@gmail.com Médico en Libre Ejercicio de la Profesión

(Quito - Ecuador) DOI: $10.1159 / 000330934$

\section{RESUMEN}

El absceso prostático es una patología poco frecuente con incidencia del 0,5\% de todas las patologías prostáticas con mortalidad del 1 al 16\%, se presenta un caso en paciente de 68 años, diabético, con síntomas urinarios irritativos del tracto urinario inferior, con retención urinaria aguda de tórpida evolución que fue tratado y resuelto mediante 
tratamiento antibiótico de amplio espectro bajo internación domiciliaria en contexto de pandemia COVID-19, el objetivo del estudio es dar a conocer la presentación clínica y las herramientas diagnósticas para el correcto tratamiento. Se realizó búsqueda bibliográfica actualizada sobre la patología en las principales bases de datos disponibles.

Palabras Clave: Absceso Prostático, Próstata, Enfermedad de la próstata 


\title{
Prostate abscess: diagnosis and clinical treatment
}

\begin{abstract}
About a case
ABSTRACT

Prostate abscess is a rare pathology with an incidence of $0.5 \%$ of all prostate pathologies with mortality from 1 to $16 \%$, a case is presented about 68 -year-old diabetic patient with lower urinary symptoms with acute urinary retention with torp evolution that was treated and resolved by means of broad-spectrum antibiotic treatment under home hospitalization in the context of a COVID-19 pandemic, the objective of the study is to publicize the clinical presentation and diagnostic tools for the correct treatment, for this purpose a bibliographic search was carried out updated on pathology.
\end{abstract}

Key Words: Prostate Abscess, Prostate, Prostatic Diseases

Artículo recibido: 05 de Mayo 2021 Aceptado para publicación: 20 de Junio 2021 Correspondencia: julioalvarezuro@gmail.com Conflictos de Interés: Ninguna que declarar 


\section{INTRODUCCIÓN}

El absceso prostático en definición es una o varias colecciones purulentas ubicadas en la glándula prostática, esta una patología poco frecuente con una incidencia anual del $0.5 \%$ de todas las patologías prostáticas, su presentación ha disminuido sobre todo por la aparición de antibióticos de amplio espectro y su buena penetración en la próstata. (Antonio Jiménez-Pachecoa, 2015)

Es una patología de difícil diagnóstico, con presentación de sintomatología urinaria baja con respuesta tórpida a tratamiento clínico inicial, con posibles complicaciones que incluso pueden llegar a sepsis o la muerte.

\section{Caso Clínico}

Paciente de 68 años, diabético tipo II, con antecedente de amputación de miembro inferior izquierdo, que acude por emergencia con cuadro de retención aguda de orina asociado a hiperplasia prostática benigna, se decide colocación de sonda vesical siliconada $18 \mathrm{fr}$ y se inicia tratamiento con tamsulosina, se llama a control en 8 días, se retira sonda y se aguarda a micción voluntaria, 24 horas después acude nuevamente a sala de emergencia por dificultad urinaria que se acompaña de disuria, ante imposibilidad de sondaje por parte de personal de enfermería es valorado por el servicio de urología, se realiza tacto prostático el cual es normal sin dolor a la digitopresión, colocando sonda vesical y se instaura tratamiento con norfloxacina 400mg más fenazopiridina $200 \mathrm{mg}$ cada 12 horas. Acude a control 7 días después, refiere dolor para sentarse, molestias para deambular y sobre todo se queja de dolor en glúteo izquierdo, evidenciándose eritema, calor y dolor a la palpación en el glúteo, se solicita eco de partes blandas evidenciándose colección de $110 \mathrm{ml}$ sin evidenciar su origen, se retira sonda vesical e inmediatamente se obtiene debito uretral purulento espontáneo aproximadamente $60 \mathrm{ml}$, se solicita tac contrastada de abdomen y pelvis (Figura 1) objetivándose absceso prostático que se extiende hasta el glúteo izquierdo, se solicita examen de laboratorio donde se evidencia leucocitosis de 24000 leucocitos con neutrofilia del 95\%, PCR de 96, se sugiere internación para iniciar tratamiento endovenoso de amplio espectro, sin embargo por encontrarnos cursando pandemia de COVID 19, el paciente se niega a ser hospitalizado, se decide internación domiciliaria con antibioticoterapia a base de ceftriaxona $1 \mathrm{~g}$ cada 24 horas y ante la persistencia de dificultad urinaria se coloca sonda vesical, se cita a control en 72 horas, se encuentra persistencia de marcadores de inflamación elevados con PCR de 75, 
leucocitosis de 21000. Urocultivo reporta flora polimicrobiana, paciente persiste con rechazo a la internación hospitalaria, se decide continuar con ceftriaxona $1 \mathrm{~g}$ cada 12 horas y se agrega clindamicina $600 \mathrm{mg}$ cada 8 horas, a las 72 horas se observó mejoría clínica y disminución de marcadores inflamatorios, se decide completar esquema de 14 días de antibiótico, al día 15 paciente se muestra asintomático, se retira sonda obteniendo micción voluntaria, laboratorio dentro de parámetros normales, se decide alta del paciente con tratamiento ambulatorio por 4 semanas a base de ciprofloxacina 500mg cada 12 horas.

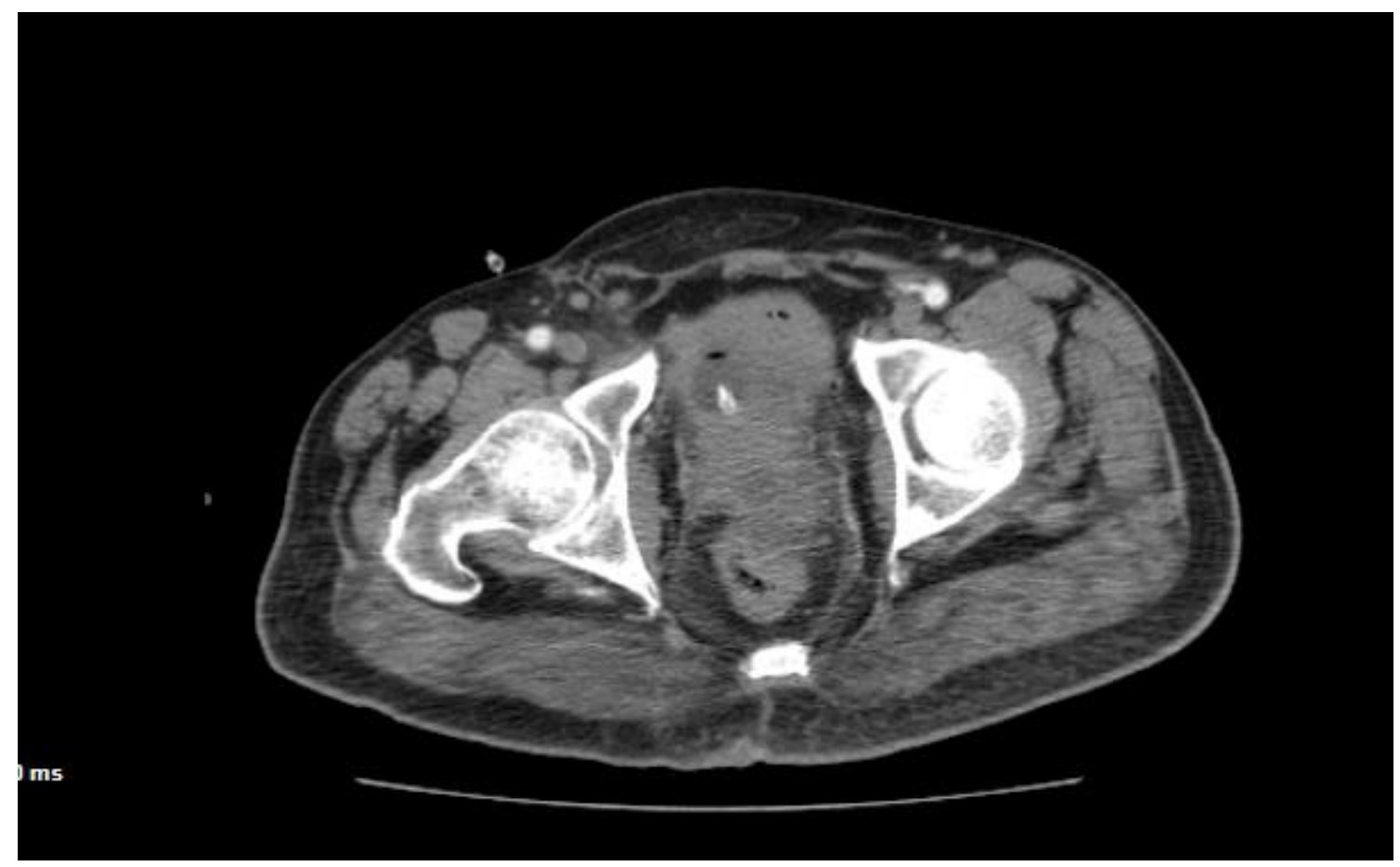

(Figura 1). TAC de Pelvis: La próstata muestra colecciones líquidas heterogéneas, que se extienden hacia el recto, grasa perirrectal y región anal, sugestivas de abscesos loculados.

\section{MATERIALES Y MÉTODOS}

Para la elaboración del presente manuscrito se realizó una búsqueda bibliográfica en las principales bases de datos como ScienceDirect, PubMed, Scielo, Google Scholar, se seleccionaron 6 artículos para el análisis bibliográfico y discusión.

\section{DISCUSIÓN}

El absceso prostático es una patología relativamente infrecuente, su presentación ha disminuido notablemente a causa de los antibióticos de amplio espectro, representando al $0.5 \%$ de todas las patologías de la glándula prostática (Antonio Jiménez-Pachecoa, 2015), esta patología afecta principalmente a hombres mayores de 50 años con enfermedades 
crónicas principalmente diabéticos, inmunodeprimidos, enfermos renales crónicos, prostatitis, trauma perineal, portadores de sondas vesicales permanente, biopsia de próstata.

El mecanismo de infección puede ser por vía ascendente o por vía hematógena, siendo la más común por vía ascendente a causa de enterobacterias, principalmente E. Coli en un 70\% de los casos (Paula Andrea Peña, 2019), por vía hematógena se da en pacientes con focos infecciosos a distancia, en este caso se encuentra producido en su mayoría por Staphylococcus aureus meticilinorresistente (SAMR), Citrobacter sp., Mycobacterium tuberculosis y Candida sp (Paula Andrea Peña, 2019).

La presentación clínica es inespecífica y puede ser variada, generalmente los pacientes presentan síntomas urinarios irritativos como disuria, polaquiuria o tenesmo, o pueden presentar síntomas obstructivos como disminución del chorro de orina, esfuerzo para orinar o retención aguda de orina. También se puede presentar cuadro clínico con fiebre o dolor perineal. (Antonio Jiménez-Pachecoa, 2015) (Paula Andrea Peña, 2019) (Serrano Frago P, 2006). En cuanto al examen físico lo más común es que al tacto prostático nos encontremos con próstatas dolorosas a la palpación, induradas e incluso normales. (Tolosa-Alvarez AB, 2015)

Para el diagnóstico del absceso prostático, además de la presentación clínica, contamos con la ecografía transrectal que nos aporta mayor información que la ecografía abdominal, este estudio es de elección por su accesibilidad y bajo costo, también podemos definir el diagnóstico con RMN o TAC. (Paula Andrea Peña, 2019) (Tolosa-Alvarez AB, 2015) El urocultivo es una prueba de laboratorio importante que nos ayudará a identificar la bacteria causante de la enfermedad y decidir el tratamiento antibiótico adecuado para cada caso.

Dentro de las complicaciones del absceso prostático podemos observar drenaje espontáneo hacia la uretra o el recto, shock séptico, e incluso la muerte, esta última varía entre el 1 al 16\% (Antonio Jiménez-Pachecoa, 2015) (Tolosa-Alvarez AB, 2015)

El tratamiento en todos los casos se basa en antibioticoterapia de amplio espectro, se recomienda iniciar tratamiento de la fase aguda con Ceftriaxona $1 \mathrm{~g} / 12 \mathrm{~h}$ asociada a metronidazol $500 \mathrm{mg} / 8 \mathrm{~h}$ iv o Imipenem-cilastatina $1 \mathrm{~g} / 12 \mathrm{~h}$ iv. o Ciprofloxacino 400 $\mathrm{mg} / 12 \mathrm{~h}$ asociado a vancomicina $1 \mathrm{~g} / 12 \mathrm{~h}$ iv Pasada la fase aguda se continúa con ciprofloxacino $500 \mathrm{mg} / 12 \mathrm{~h}$ o levofloxacino $500 \mathrm{mg} / 24$ h durante 4 semanas más por vía 
oral. En paciente con abscesos menor a $1 \mathrm{~cm}$ se recomienda antibioticoterapia y conducta expectante y en aquellos casos en los cuales el absceso es mayor a $1 \mathrm{~cm}$ se recomienda drenaje percutáneo guiado por eco transperineal o transrectal de primera opción, o drenaje transuretral mediante RTU, e incluso se puede llegar a necesitar drenaje a cielo abierto en en próstatas de gran tamaño o con afectación extra prostática.

\section{CONCLUSIONES}

El absceso de próstata es una patología poco frecuente y de difícil diagnóstico clínico por su presentación inespecífica, usualmente se confunde con infección del tracto urinario de mala evolución, se requiere estudios de imagen para su diagnóstico definitivo.

El tratamiento de esta patología en abscesos menores de $1 \mathrm{~cm}$ se basa en conducta expectante con tratamiento antibiótico de amplio espectro, en abscesos de mayor tamaño está indicado el drenaje guiado por eco transperineal o transrectal, en casos persistentes se aconseja drenaje transuretral mediante RTU e incluso se puede llegar a requerir drenaje mediante cirugía abierta. (Antonio Jiménez-Pachecoa, 2015) (Paula Andrea Peña, 2019) (Tolosa-Alvarez AB, 2015)

En el caso que se presentó, se decidió conducta expectante más antibioticoterapia de amplio espectro porque el absceso fue drenado espontáneamente a través de la uretra, además el paciente presentó mejoría clínica y normalización de los parámetros de laboratorio por lo que no fue necesario el drenaje quirúrgico.

\section{REFERENCIAS}

Antonio Jiménez-Pachecoa, Araceli Jiménez-Pacheco, Manuel Verdú-Martínez, Alfonso

López-Luque, (2015) Drenaje transperineal ecodirigido de un absceso prostático. A propósito de un caso y revisión de la literatura, Rev Int Androl, 74-78.

Paula Andrea Peña, Germán Patiño (2019) Absceso prostático: revisión de la literatura, Univ. Med.

https://doi.org/10.11144/Javeriana.umed 60-2.abs

Serrano Frago P, Allepuz Losa C, Fantova Alonso A, Marco Valdenebro A, Allué López M, Rioja Sanz LA, (2006), Actualidad en manejo de abcesos prostáticos: a propósito de un caso, Actas Urol Esp, 720-72.

Tolosa-Alvarez AB, et al. (2015), Absceso prostático: caso clínico y revisión de la literatura. Semergen.; 922. http://dx.doi.org/10.1016/j.semerg.2015.06.01 
Angel Arrabal-Polo Antonio Jimenez-Pacheco, Miguel Arrabal-Martin, (2012), Percutaneous Drainage of Prostatic Abscess: Case Report and Literature Review Miguel, Urol Int,118-120 